\title{
Flunixin Meglumine Enhanced Bone Fracture Healing in Rabbits Associated with Activation of Early Collagen Deposition and Enhancement of Vascular Endothelial Growth Factor Expression
}

\author{
Mohamed Elgendy ${ }^{1}$, Gamal Elsayad ${ }^{1}$, Magdi Seleim ${ }^{1}$, Walied Abdo ${ }^{2}$, Roua S. Baty ${ }^{3}$, \\ Ehab Kotb Elmahallawy $4, *$ (D) and Ayman Atiba 1,*(D)
}

Citation: Elgendy, M.; Elsayad, G.; Seleim, M.; Abdo, W.; Baty, R.S.; Elmahallawy, E.K.; Atiba, A. Flunixin Meglumine Enhanced Bone Fracture Healing in Rabbits Associated with Activation of Early Collagen Deposition and Enhancement of Vascular Endothelial Growth Factor Expression. Animals 2021, 11, 2834. https://doi.org/10.3390/ani11102834

Academic Editors: Francesco Macrì, Simona Di Pietro and Cecilia Vullo

Received: 25 August 2021

Accepted: 22 September 2021

Published: 28 September 2021

Publisher's Note: MDPI stays neutral with regard to jurisdictional claims in published maps and institutional affiliations.

Copyright: (c) 2021 by the authors. Licensee MDPI, Basel, Switzerland. This article is an open access article distributed under the terms and conditions of the Creative Commons Attribution (CC BY) license (https:// creativecommons.org/licenses/by/ $4.0 /)$.
1 Department of Surgery, Anesthesiology and Radiology, Faculty of Veterinary Medicine, Kafrelsheikh University, Kafrelsheikh 33516, Egypt; Mohamed_elgendy@vet.kfs.edu.eg (M.E.); elsayad@vet.kfs.edu.eg (G.E.); magdy.saleem@vet.kfs.edu.eg (M.S.)

2 Department of Pathology, Faculty of Veterinary Medicine, Kafrelsheikh University, Kafr Elsheikh 33516, Egypt; walid.eid@vet.kfs.edu.eg

3 Department of Biotechnology, College of Science, Taif University, P.O. Box 11099, Taif 21944, Saudi Arabia; rsbaty@tu.edu.sa

4 Department of Zoonoses, Faculty of Veterinary Medicine, Sohag University, Sohag 82524, Egypt

* Correspondence: eehaa@unileon.es (E.K.E.); ayman.otiba@vet.kfs.edu.eg (A.A.)

Simple Summary: Postfracture treatment with nonsteroidal anti-inflammatory drugs might result in delayed healing. This study was aimed to evaluate and compare the effects of flunixin meglumine (FM) and ketoprofen on bone fracture healing in rabbits. A simple unilateral diaphyseal fracture was made and followed by fixation by K-wire. Healing was evaluated with radiography, histopathology, and immunohistochemistry. Interestingly, the results revealed that FM enhanced bone fracture healing combined with the activation of early collagen deposition, marked angiogenesis, and enhanced vascular endothelial growth factor. However, ketoprofen delayed bone fracture healing. These findings provide novel baseline information about the potential beneficial effects of FM on bone fracture healing cases.

Abstract: Nonsteroidal anti-inflammatory drugs (NSAIDs) are among the most commonly used postoperative analgesics, antipyretics, and anti-inflammatories, and they help prevent blood clotting. However, most NSAIDs delay bone healing. This study was aimed to investigate bone healing in a rabbit animal model by assessing the ability of flunixin meglumine (FM) and ketoprofen to induce fracture healing by examining histology, radiological changes, and vascular endothelial growth factor (VEGF) immunostaining during bone healing. For this purpose, 24 New Zealand rabbits were assigned to three groups: the control group, the FM group, and the ketoprofen group. Our results revealed that there were no intraoperative complications, and all surviving rabbits achieved fullweight bearing. Significant periosteal reaction and callus formation were confirmed at 2 postoperative weeks. Interestingly, FM enhanced callus formation, bone union, and remodeling in the FM group compared to the control and ketoprofen groups. FM enhanced bone healing through early collagen deposition and marked angiogenesis process activation by increasing the expression of VEGF. Our findings demonstrated, for the first time, the potential imperative action of FM in the bone healing process rather than other NSAIDs in animals.

Keywords: flunixin meglumine; ketoprofen; bone healing; fracture; rabbit

\section{Introduction}

The bone healing process involves multi-sequential events associated with numerous cellular functions that promote mineralization of the fracture site followed by remodeling 
to return the affected bone to its original structure [1]. In the literature, many postoperative drugs, including antibiotics [2] and anti-inflammatory drugs [3-6], have been used in different stages of the healing process. Among them, anti-inflammatory drugs have been extensively used as a painkiller to ensure fracture site immobility. However, numerous studies have demonstrated that steroidal and nonsteroidal anti-inflammatory drugs (NSAIDs) inhibit healing in soft and hard tissues [3,4]. Furthermore, various reports have suggested that NSAIDs interfere with bone healing, though others have contradicted these findings [7]. Celecoxib [8,9] and aspirin [10] inhibit bone healing [11,12], while ibuprofen [13] and parecoxib [14] do not affect bone healing.

The inhibitory action of NSAIDs might result from the inhibition of prostaglandin production from arachidonic acid via either the cyclooxygenase 1 (COX-1) or cyclooxygenase 2 (COX-2) enzyme pathway $[15,16]$. COX-1 is initially involved in physiological functions such as the preservation of hemostasis and gastric protection [17]. Meanwhile, COX-2 is initially found and involved in the pathophysiological pathways such as inflammation, fever, and pain $[3,18]$. However, prostaglandins play an important role in the bone healing process, especially through the regulation of osteoblast and osteoclast functions [19]. The marked inhibition of prostaglandin production decreases bone formation rate [20].

Ketoprofen is a potent nonselective COX-1 inhibitor that is extensively used in small animal medicine [15]. Ketoprofen is a nonselective NSAID used to decrease inflammation, pain, and fever, and it has analgesic effects. Data regarding the effect of ketoprofen on bone healing have been variable and controversial. Ketoprofen may not affect bone healing, especially in small doses for a short time [21]. In a study of the effects of ketoprofen on lumbar spinal fusion healing, It was revealed that using a single dose after intertransverse spinal fusion has no effect on bone healing [22]. Flunixin meglumine (FM) is a nonselective NSAID used as a painkiller, antifever, anti-inflammatory, and antitoxemic [23-25]. Few studies have explored the effect of FM on the soft tissue healing process. A previous study reported that FM promotes tendon healing by increasing fibroblast and blood supply to the wound site [23]. To the best of our knowledge, there has been no study on the effect of FM on bone healing. Growth factors play pivotal roles in the bone healing process [26]. The preservation of bone blood flow is considered one of the main mechanisms that promotes bone healing [26]. Vascular endothelial growth factor (VEGF) expression is essential for neurovascular development, i.e., vasculogenesis or the de novo production of blood vessels from mesenchymal precursor cells [26-28]. Given this information, the authors of this study aimed to determine the potential effects of ketoprofen and FM on bone healing in a rabbit femoral fracture model. The authors assessed these effects through a series of methods, including routine X-ray, histopathology, collagen deposition, and VEGF immunohistochemistry.

\section{Materials and Methods}

\subsection{Ethical Committee Approval}

The Research Ethics Committee of the Faculty of Veterinary Medicine, Kafrelsheikh University, reviewed and approved the procedures and protocols involved in both the animal welfare and surgical techniques of this study under approval number KFS-2020/7. The ethical approval code number is KFS-2020/7.

\subsection{Animals}

A total of 24 New Zealand rabbits at ten weeks of age and with bodyweight ranging from 2000 to $2200 \mathrm{~g}$ were used in this study. Rabbits were individually housed in a battery cage system with a natural day/night cycle at $21-28{ }^{\circ} \mathrm{C}$. Rabbits had free access to complete commercial rabbit diets (Ibex International Co., Ltd., Nubaria, Egypt) and clean water throughout the study period. Two weeks before the start of the study, the rabbits were acclimatized. 


\subsection{Surgical Procedures}

Figure 1 illustrates the surgical procedures. Rabbits were anesthetized via the intramuscular injection of $5 \mathrm{mg} / \mathrm{kg}^{-1}$ bwt of xylazine hydrochloride (Xylaject, Adwia, New Cairo, Egypt) and $40 \mathrm{mg} / \mathrm{kg}^{-1}$ bwt of ketamine hydrochloride (Ketamine, Sigma, Cairo, Egypt) [23,29]. The right hind limb of each rabbit was prepared for aseptic surgical intervention. After a craniolateral skin incision, the biceps femoris was caudally retracted to expose the vastus lateralis muscle. The fascial septum of the vastus lateralis was incised, followed by a reflection of the vastus lateralis from the surface of the femur to expose the femoral diaphysis $[30,31]$. The fracture was made via the exposure of the femoral diaphysis using the surgical Saw Bojin BJ4101, and K-wire (size $1.2 \mathrm{~mm}$ ) was introduced into the bone for fixation. The suturing of the muscle layer was performed with simple continuous absorbable polyglycolic acid sutures that were braided and coated with violet 4/0 (SURGICRYL-PGA, SMI AG, Vith., Belgium), and then the skin was sutured using simple interrupted absorbable polyglycolic acid sutures that were braided and coated with violet 2/0 (Surgicryl PGA, SMI AG, Vith., Belgium) [30]. The bandage was applied directly after surgery and kept for one week using a soft cotton pad, tongue depressor, gauze, and self-adhesive tape. All groups were injected with $10000 \mathrm{IU} / \mathrm{kg}$ bwt of penicillin and $10 \mathrm{mg} / \mathrm{kg}$ bwt of streptomycin (Pen \& Strep Norbrook, West Sussex, UK) once daily Subcutaneous $(\mathrm{S} / \mathrm{C})$ for 5 successive days.

\subsection{Animal Grouping}

Animals were randomly divided into 3 groups as follows: a control group in which animals received saline solution as a placebo for 5 successive days, an FM group in which animals were intramuscularly injected with $2 \mathrm{mg} / \mathrm{kg}$ bwt of FMne (Finadyne ${ }^{\circledR}$, MSD Animal Health, Walton, UK) once daily for 5 successive days, and a ketoprofen group in which animals were intramuscularly injected 2 with $\mathrm{mg} / \mathrm{kg}$ bwt of ketoprofen (Ketolgin, Amoun, Al Obour, Egypt) once daily for 5 successive days [1,21,23].

\subsection{Clinical Evaluation}

Animals were clinically evaluated for body temperature, food intake, and daily activity during the week after surgery until external bandage removal. After this period, the animals were evaluated twice a week throughout the experimental period. The evaluation technique consisted of inspecting the external wound for dehiscence, edema, or pus; palpating the limbs by estimating the pain and muscular atrophy of the quadriceps muscle group of the operated limb; and comparing the operated limb with the contralateral limb [29].

\subsection{Radiography}

Radiography was performed using GXR $52 \mathrm{~S}$, an X-ray apparatus (DRGEM Co., Ltd., Seoul, Korea). The X-ray beam was applied using the following factors: $40 \mathrm{KV}, 25 \mathrm{MA}$, and 1.25 MAS. Two radiographic views (ventrodorsal and lateral) were taken. The $\mathrm{X}$-ray was performed before and after surgical procedures at $0,2,4,6$, and 8 weeks after operation, as mentioned in [1].

\subsection{Radiographic Scoring}

The scoring system of this study was based on the point system described in [30]. It involved the quantitative assessment of periosteal reaction, bone union, and remodeling. Periosteal callus formation was given 4 when it was full, 3 for a moderate reaction, 2 for mild reaction, 1 for a minimum reaction, and 0 for no periosteal callus formation. The bone union was designated as 3 for complete bridging, 2 for moderate bridging more than $50 \%$ of the gap, 1 for slight union less than $50 \%$ of the gap, and 0 for nonunion. Bone remodeling was given 3 for advanced remodeling, 2 for moderate remodeling, 1 for early remodeling, and 0 for no remodeling. Images were scored by an independent radiologist who was blinded to the animal's treatment. 

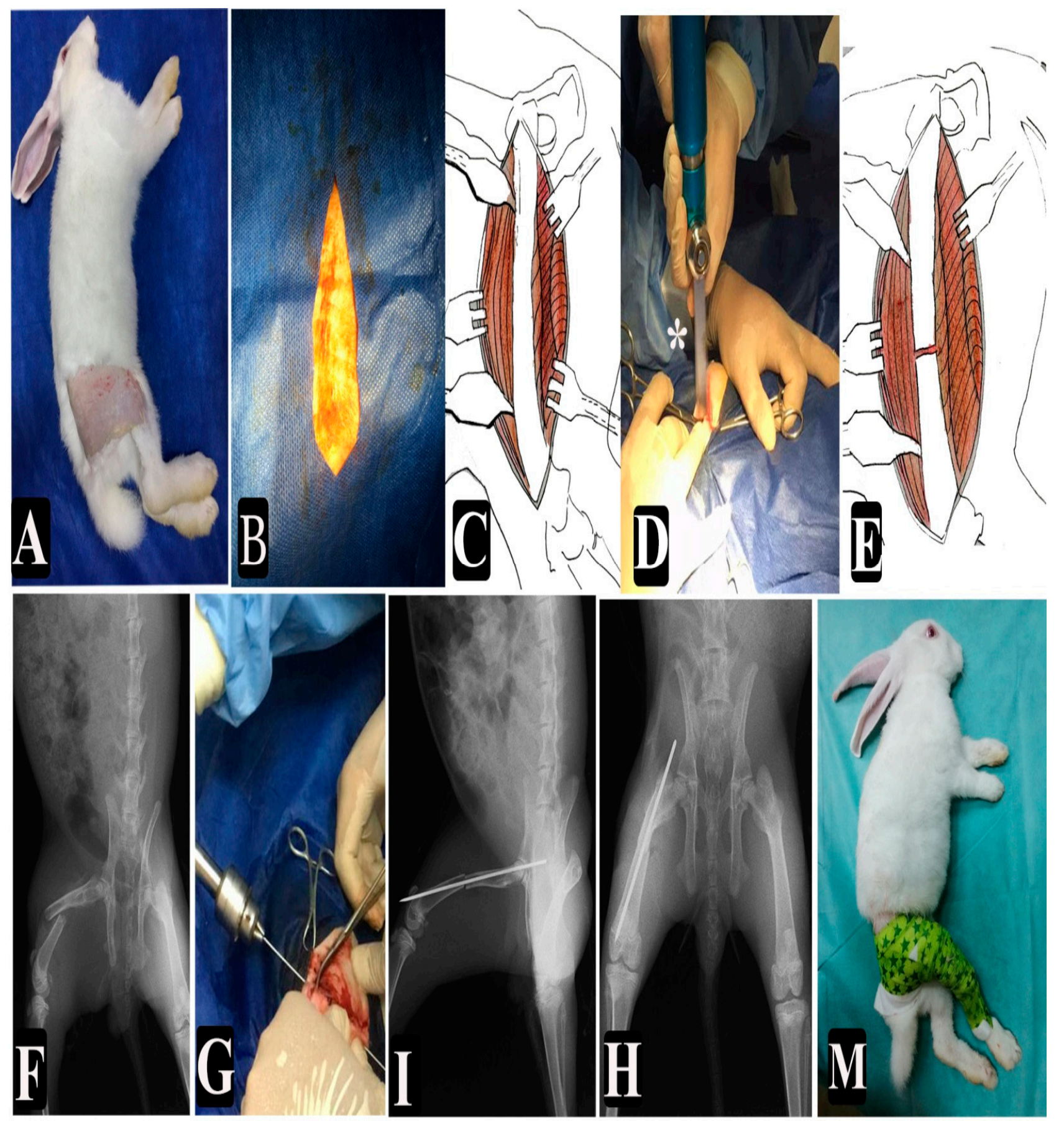

Figure 1. (A-M) Surgical procedures: (A) clipping and shaving of the femur region of the right limb of the rabbit, (B) draping and disinfection, (C) exposure of the femur bone, (D) making the fracture by the orthopedic saw (* refers to fracture site in the midshaft of the femur), (E) a diagram showing the site of fracture in midshaft, (F) X-ray film directly after a fracture, (G) introduction of K-wire into the femur, (I) X-ray film lateral view, (H) X-ray film ventrodorsal view, and (M) bandage application.

\subsection{Histopathology}

Animals were euthanized by overdose anesthesia 4 and 8 weeks after the operation. At a rate of 4 specimens per each group (1 specimen/animal) during two time points of treatment, the specimens were subjected to the histopathological examination of osteogenesis at the fracture site using hematoxylin and eosin (H\&E) stain and Masson's trichrome stain [32]. Histopathological grading was performed according to the Lane and Sandhu histopathological scoring system, modified by Heiple et al. [33] and Bigham et al. [34], 
who used 20-point grading score to assess proximal union, distal union, cancellous bone, cortical bone, and marrow (4 points for each category).

\subsection{Immunohistochemical Procedures}

The immunohistochemical staining procedures followed that of Saber et al., 2019 [35]. Sections were dewaxed and immersed in a solution of a $0.05 \mathrm{M}$ citrate buffer $(\mathrm{pH}$ 6.8) for antigen retrieval. These sections were treated with $0.3 \% \mathrm{H}_{2} \mathrm{O}_{2}$ and protein block, and they were incubated with polyclonal rabbit anti-VEGF antibody (cat. no. PA5-16754, dilution 1/100, Thermo Fisher Scientific, Waltham, MA, USA). After being rinsed with phosphate-buffered saline, they were incubated with a goat anti-rabbit secondary antibody (cat. no. K4003, EnVision $+^{\mathrm{TM}}$ System Horseradish Peroxidase Labelled Pomer, Dako, Thermo Fisher Scientific, Waltham, MA, USA) for 30 minutes at room temperature. Slides were then visualized with a DAB kit and eventually stained with Mayer's hematoxylin as a counterstain. The staining intensity was assessed on a threshold basis using ImageJ Analysis software (NIH, Bethesda, MD, USA) and is presented as the percentage of positive area per $\mathrm{mm}^{2}$ in about 8 high power fields [35].

\subsection{Statistical Analysis}

Data were analyzed using GraphPad Prism 6 statistical software (GraphPrism Software, La Jolla, CA, USA). The statistical significance among groups was tested by a one-way analysis of variance (ANOVA) using the nonparametric Kruskal-Wallis H test followed by Dunn's multiple comparison test. The $p$ value was considered significant at less than 0.05 .

\section{Results}

\subsection{Radiographic Findings}

Table 1 presents the scores of radiographic findings according to the timeline. The radiographic findings of the control group at 2 postoperative weeks showed mild soft callus formation, with the noncomplete bridging bone union increasing over time. Meanwhile, the ketoprofen group revealed weak callus formation without a bone union. The FM group exhibited moderate soft callus formation with a noncomplete bridging bone union that increased over time (Figure 2). The callus formation score in the FM group (3.14 \pm 0.51$)$ was significantly higher $(p<0.05)$ than those in the ketoprofen group $(2 \pm 0.84)$ and the control group $(2.5 \pm 0.54)$. In stark contrast, callus formation was significantly lower $(p<0.05)$ in the ketoprofen group $(2 \pm 0.84)$ than that in the control group $(2.5 \pm 0.54)$. Importantly, the bone union score in the FM group $(2.40 \pm 0.40)$ was significantly higher $(p<0.05)$ than those in the ketoprofen group $(0.83 \pm 0.40)$ and the control group $(1.66 \pm 0.51)$. However, the bone union was significantly lower $(p<0.05)$ in the ketoprofen group $(0.83 \pm 0.40)$ than that in the control group $(1.66 \pm 0.51)$. At 4 postoperative weeks, the control group showed mild callus formation and bone union, with mild to moderate bridging between the bone edges. The ketoprofen group showed less bone callus formation than the other 2 groups and nonunion between the bone edges. The FM group showed greater mild soft callus formation than that in the control group and complete bone union. The callus formation score in the FM group $(3.13 \pm 0.51)$ was significantly higher $(p<0.05)$ than those in the ketoprofen group (1.66 \pm 0.82$)$ and the control group (2.67 \pm 0.52$)$. Callus formation was significantly lower $(p<0.05)$ in the ketoprofen group $(1.66 \pm 0.82)$ than in the control group $(2.67 \pm 0.52)$. The bone union score in the FM group $(2.42 \pm 0.41)$ was significantly higher $(p<0.05)$ than those in the ketoprofen group $(1.17 \pm 0.75)$ and control group $(1.83 \pm 0.75)$. In contrast, the bone union was significantly lower $(p<0.05)$ in the ketoprofen group $(1.17 \pm 0.75)$ than that in the control group $(1.83 \pm 0.75)$. 
Table 1. Score of radiographic findings.

\begin{tabular}{|c|c|c|c|c|c|c|c|c|c|c|}
\hline \multirow{2}{*}{ Timeline } & \multicolumn{3}{|c|}{ Callus Formation } & \multicolumn{3}{|c|}{ Bone Union } & \multicolumn{3}{|c|}{ Bone Remodeling } & \multirow{2}{*}{$p$ Value } \\
\hline & Control & Ketoprofen & FM & Control & Ketoprofen & FM & Control & Ketoprofen & FM & \\
\hline 2 weeks & $2.5 \pm 0.54$ & $2 \pm 0.84$ & $3.14 \pm 0.51$ & $1.66 \pm 0.51$ & $0.83 \pm 0.40$ & $2.40 \pm 0.40$ & - & - & - & $p<0.05$ \\
\hline 4 weeks & $2.67 \pm 0.52$ & $1.66 \pm 0.82$ & $3.13 \pm 0.51$ & $1.83 \pm 0.75$ & $1.17 \pm 0.75$ & $2.42 \pm 0.41$ & - & - & - & $p<0.05$ \\
\hline 6 weeks & $3.17 \pm 0.75$ & $1.83 \pm 0.75$ & $2.29 \pm 0.52$ & $2.33 \pm 0.52$ & $1.17 \pm 0.75$ & $2.46 \pm 0.40$ & $0.33 \pm 0.52$ & $0 \pm 0$ & $1.33 \pm 0.51$ & $p<0.05$ \\
\hline 8 weeks & $2.67 \pm 0.52$ & $0.33 \pm 0.52$ & $0.59 \pm 0.52$ & $2.66 \pm 0.52$ & $0.33 \pm 0.52$ & $2.75 \pm 0.41$ & $1.33 \pm 0.52$ & $0 \pm 0$ & $2.33 \pm 0.41$ & $p<0.05$ \\
\hline
\end{tabular}

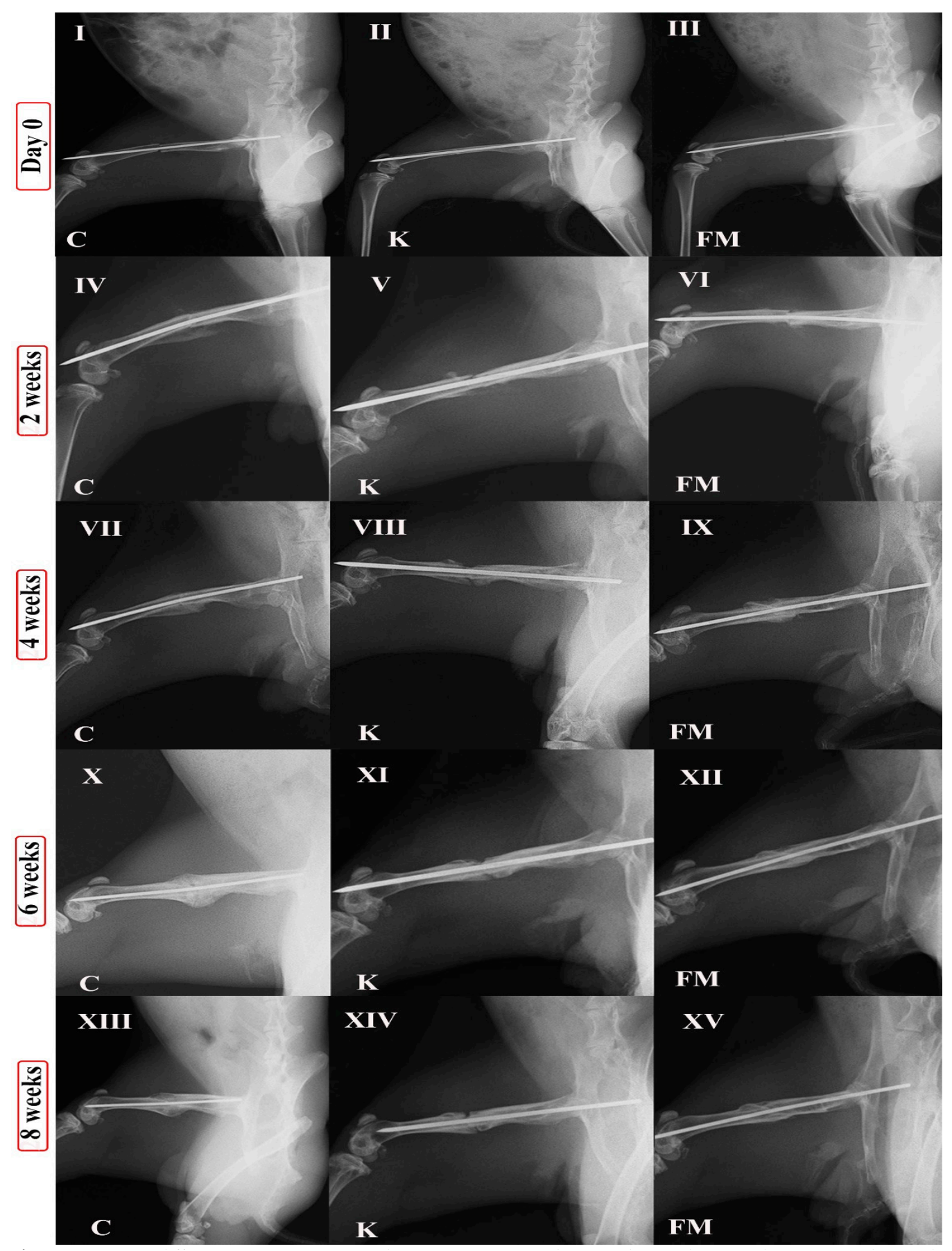

Figure 2. X-ray at different times $(0,2,4,6$, and 8 postoperative weeks). $\mathrm{C}$ indicates the control group, $\mathrm{K}$ indicates the ketoprofen group, and FM indicates the flunixin meglumine group. (I,IV,VII,X,XIII) denote control group at different times 0, 2, 4, 6, and 8 weeks postoperatively. (II,V,VIII,XI,XIV) denote ketoprofen group at different times $0,2,4,6$, and 8 weeks postoperatively. (III,VI,IX,XII,XV) denote FM group at different times $0,2,4,6$, and 8 weeks postoperatively. 
Based on the radiographic changes at 6 postoperative weeks, moderate callus formation was still present in the control group. The remodeling started in the few animals with moderate to complete bone union. Meanwhile, in the ketoprofen group, the minimal callus continued with a nonunion and no remodeling. However, the good callus started to decrease in size due to the early bone remodeling happening in approximately all FM rabbits with a complete bone union. The callus formation score in the FM group (2.29 \pm 0.52$)$ was significantly lower $(p<0.05)$ than that in the control group $(3.17 \pm 0.75)$. Moreover, the callus formation was significantly lower $(p<0.05)$ in the ketoprofen group $(1.83 \pm 0.75)$ than those in the control group $(3.17 \pm 0.75)$ and the FM group $(2.29 \pm 0.52)$. The bone union score in the FM group $(2.46 \pm 0.40)$ was significantly higher $(p<0.05)$ than those in the ketoprofen group $(1.17 \pm 0.75)$ and the control group $(2.33 \pm 0.52)$. Moreover, the bone union was significantly lower $(p<0.05)$ in the ketoprofen group $(1.17 \pm 0.75)$ compared to that in the control group $(2.33 \pm 0.52)$. Furthermore, the bone remodeling score in the FM group $(1.33 \pm 0.51)$ was significantly higher $(p<0.05)$ than those in the ketoprofen group $(0 \pm 0)$ and the control group $(0.33 \pm 0.52)$.

The callus decreased in most animals in the control group due to remodeling, with a complete bone union at 8 postoperative weeks. However, the fractured bone was close to its normal shape in the FM group because of the great remodeling and good bone union. In the ketoprofen group, there was bad remodeling with nonunion. The callus formation score in the FM group $(0.59 \pm 0.52)$ was significantly lower $(p<0.05)$ than that in the control group $(2.67 \pm 0.52)$. Moreover, callus formation was significantly lower $(p<0.05)$ in the ketoprofen group $(0.33 \pm 0.52)$ than those in the control group $(2.67 \pm 0.52)$ and the FM group (0.59 \pm 0.52$)$. Additionally, the bone union score in the FM group $(2.75 \pm 0.41)$ was significantly higher $(p<0.05)$ than that in the ketoprofen group $(0.33 \pm 0.52)$ and the control group (2.66 \pm 0.52$)$. Moreover, the bone union was significantly lower $(p<0.05)$ in the ketoprofen group $(0.33 \pm 0.52)$ than that in the control group $(2.66 \pm 0.52)$. Likewise, the bone remodeling score in the FM group $(2.33 \pm 0.41)$ was significantly higher $(p<0.05)$ than those in the ketoprofen group $(0 \pm 0)$ and the control group (1.33 \pm 0.52$)$. Figure 3 depiects the $X$-ray statistics at different times $(2,4,6$, and 8 postoperative weeks).

\subsection{Histological Findings}

\subsubsection{Fourth Week Study}

As illustrated in Figure 4, control animals showed large hematoma with the stilldefined junction of the two bone edges. The granulation tissues on both fracture sides showed entangled immature fibroblasts within an edematous matrix, with few collagens, and revealed the presence of few osteoblastic cells. Femur fracture in animals treated with ketoprofen demonstrated a marked decrease in inflammation, with the presence of cisterns of blood enclosed by fibrous connective tissues. Fractured animals treated with FM showed a marked decrease in inflammation signs, with a marked increase in the granulation tissue, revealing marked maturation of the fibrous connective tissues with a marked increase in osteoblastic activity. The newly osseous tissues were well-connected with the spongy bone.

\subsubsection{Eighth Week Study}

As shown in Figure 5, animals in different groups showed various healing attempts. Control animals showed a decrease in hematomas and inflammation, with increased remodeling and osteogenesis. The cortical bones of both sides are related to immature osseous and cartilaginous callus within a fibro-hyaline matrix. The ketoprofen-treated animals showed a marked decrease in inflammation, with the presence of a gap filled with soft callus that consisted of granulation tissues with a small amount of osteoblastic cell activity. The FM-treated animals revealed mature, organized, thick bands of spongy osseous forming well-connected cortical bones covered with a thick periosteal layer. Figure 6 illustrates the quantitative scoring of bone healing within the four and eight weeks of the study. Marked early union, callus formation, and remodeling occurred in fractured animals treated with FM. 


\subsection{Masson's Trichrome Staining}

Results of Masson's Trichrome Staining are shown in Figure 7. In the 4th week, the animals showed a variable amount of collagen. Control animals showed collagen deposition around the hematomas. Meanwhile, collagen deposition decreased on the margin of both sides of the fracture within the ketoprofen group. Interestingly, marked collagen deposition was visible within the FM-treated group (mostly within the early stage of bone healing), though it decreased in the late stage of bone healing. In the 8th week, the control and FM groups showed decreased collagen deposition with increased osseous tissues, while animals in the ketoprofen group showed late collagen deposition at the fracture sites. The quantitative scoring of collagen deposition of the 4th week's study revealed a significant increase in collagen deposition within the FM group compared to the control group $(p<0.05)$. The ketoprofen group showed a significant decrease in collagen compared to the control group $(p<0.05)$. The 8th week's study showed later collagen deposition in the ketoprofen group than that in the control and FM groups $(p<0.05)$.
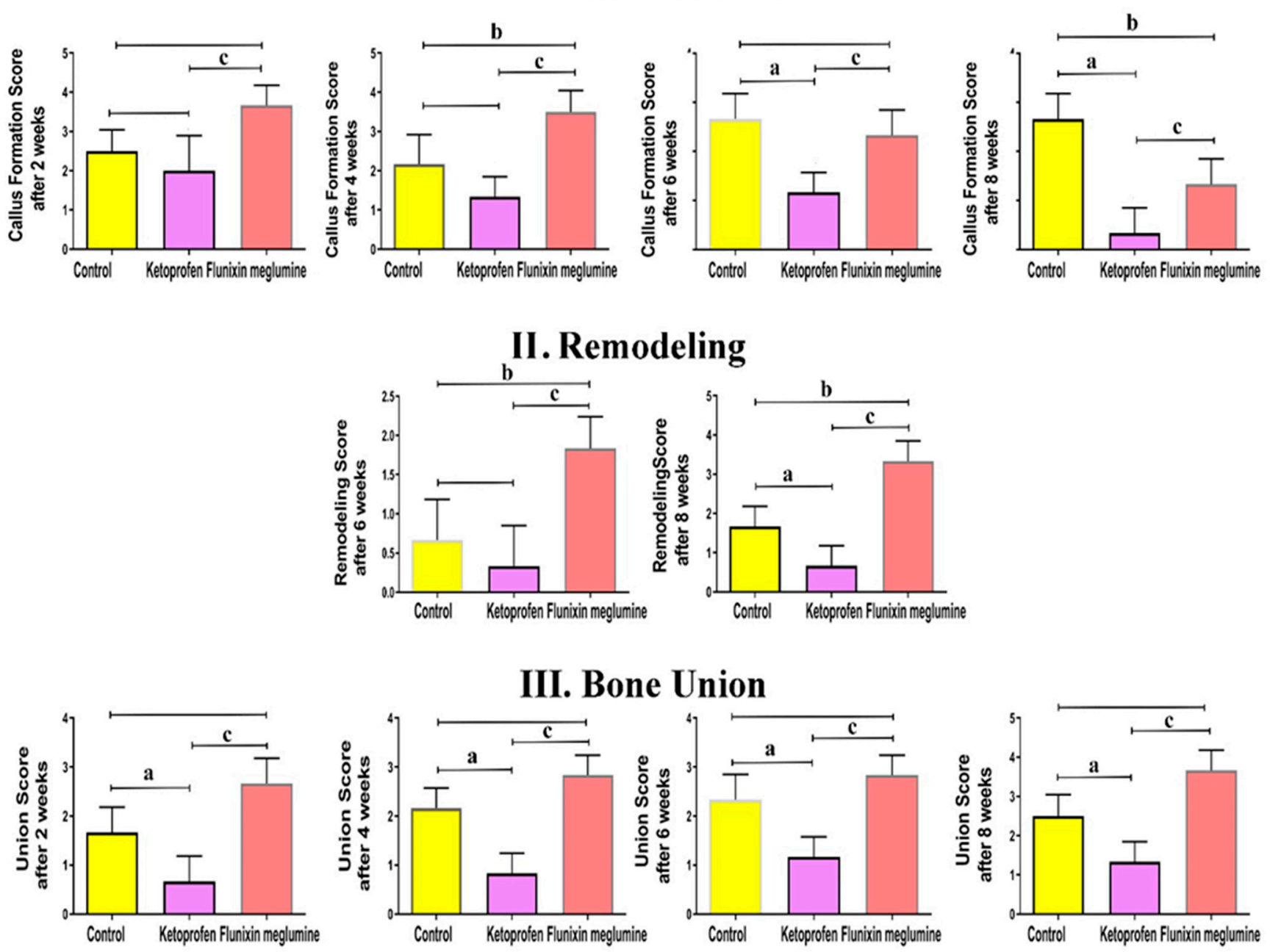

Figure 3. X-ray statistics at different times $(2,4,6$, and 8 postoperative weeks). (I): callus formation; (II): remodeling; (III): bone union. Data are expressed as mean \pm SD. Superscript letters indicate the significance level: a denotes the significant difference between the ketoprofen and the control groups, b denotes the significant difference between the FM and control groups, and c: denotes the significant difference between the FM and the ketoprofen groups $(p<0.05)$. 


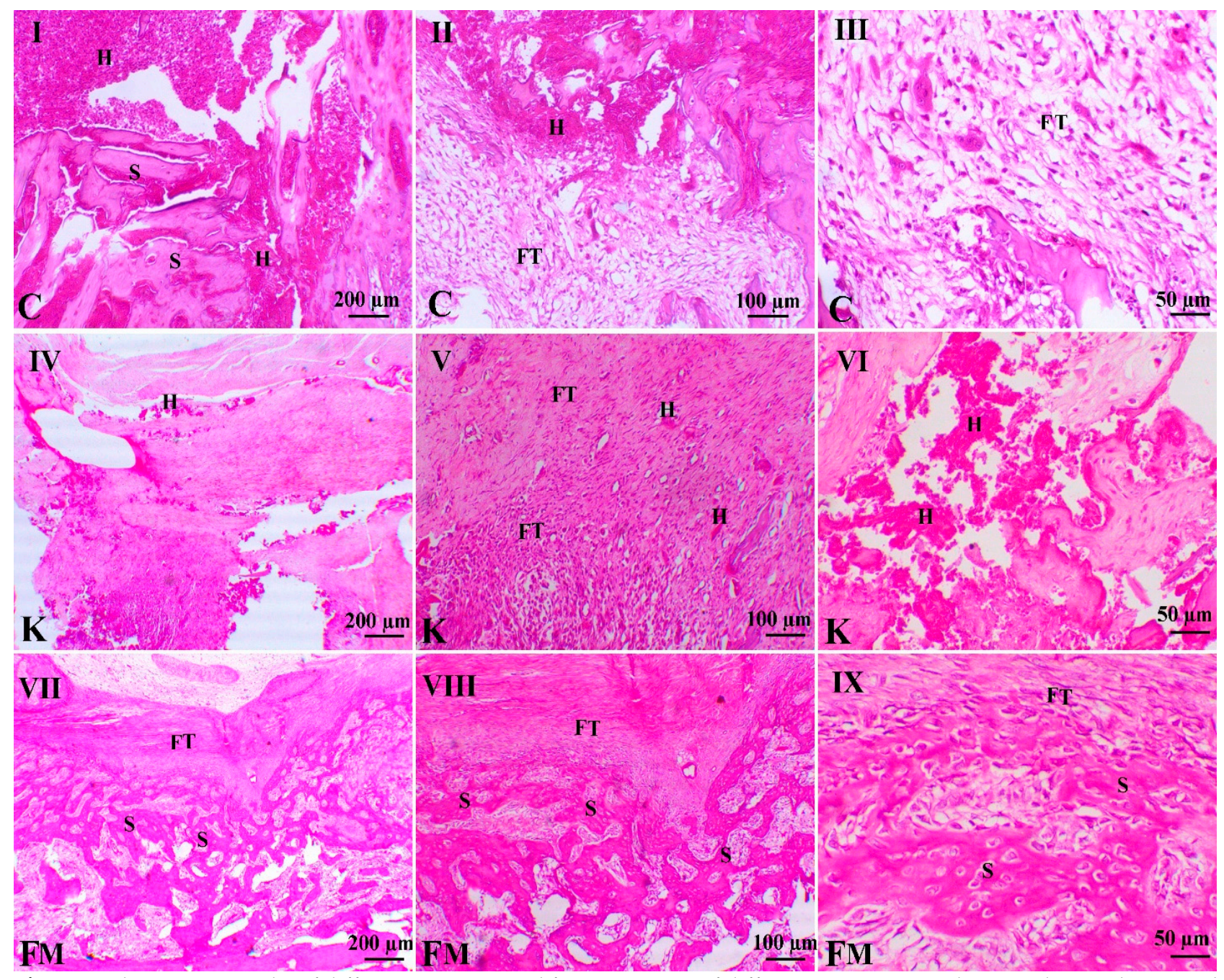

Figure 4. Photomicrographs of different H\&E-stained femur sections of different groups (4 weeks). C indicates the control group, $\mathrm{K}$ indicates the ketoprofen group, and FM indicates the flunixin meglumine group. $\mathrm{H}$ indicates hemorrhage, FT indicates fibroblasts, and S indicates osseous tissue. Bar $=200,100$, and $50 \mu \mathrm{m}$. H\&E, Bar = 200, 100 \& $50 \mu \mathrm{m}$. (I,II,III) denote control group at different magnifications power. (IV,V,VI) denote ketoprofen group at different magnifications power. (VII,VIII,IX) denote FM group at different magnifications power. 


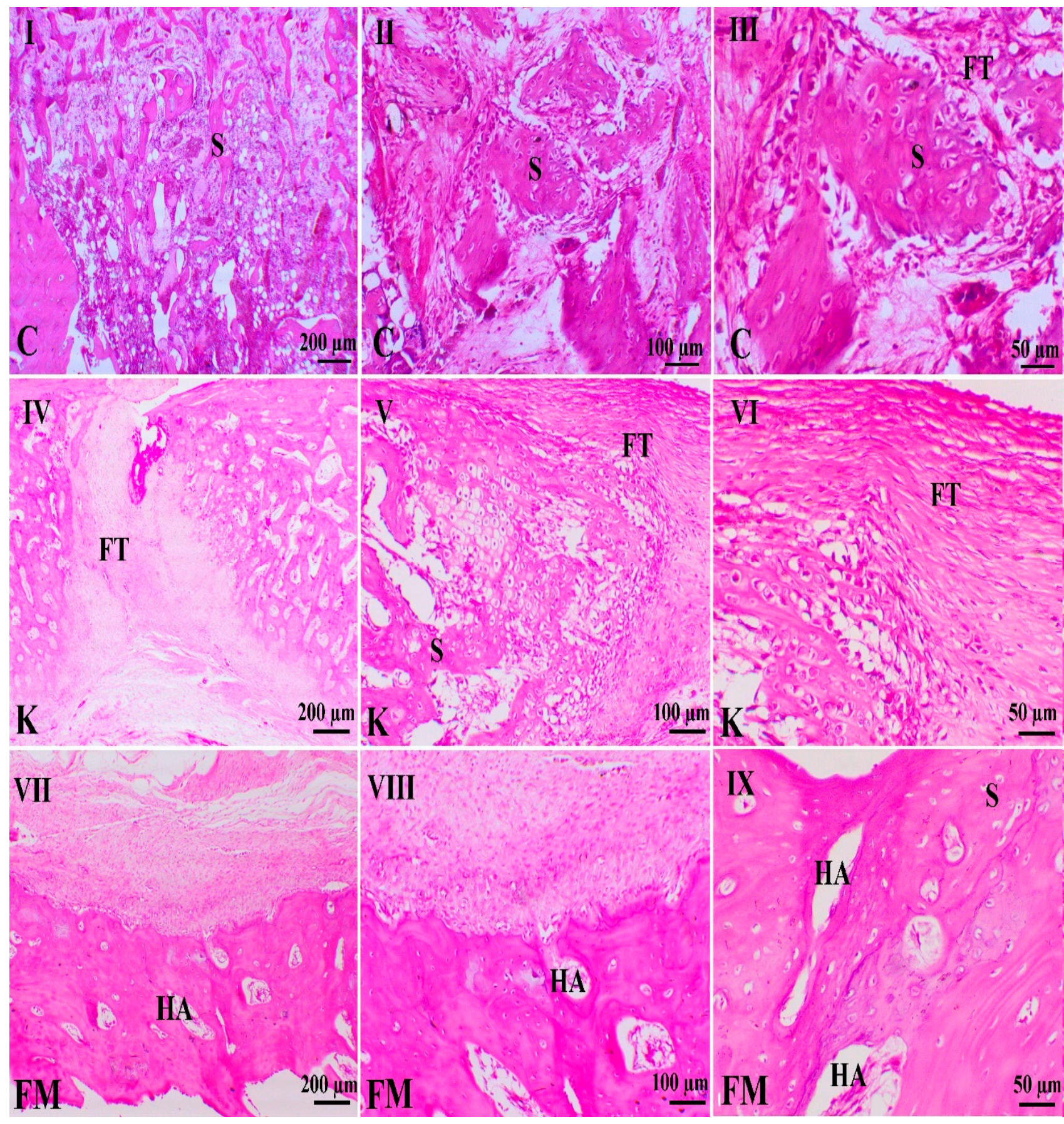

Figure 5. Photomicrographs of different H\&E-stained femur sections of different groups (8 weeks). C indicates the control group, $\mathrm{K}$ indicates the ketoprofen group, and FM indicates the flunixin meglumine group. FM treated animals showed a marked bone fracture healing activity, while the ketoprofen group revealed fibrous band between both ends of fracture site without osteogenesis features in comparison with the control group (H\&E stain). HA indicates haversian system, FT indicates fibroblasts and S indicates osseous tissue.. H\&E, Bar $=200,100 \& 50 \mu \mathrm{m}$. (I,II,III) denote control group at different magnifications power. (IV,V,VI) denote ketoprofen group at different magnifications power. (VII,VIII,IX) denote FM group at different magnifications power. 

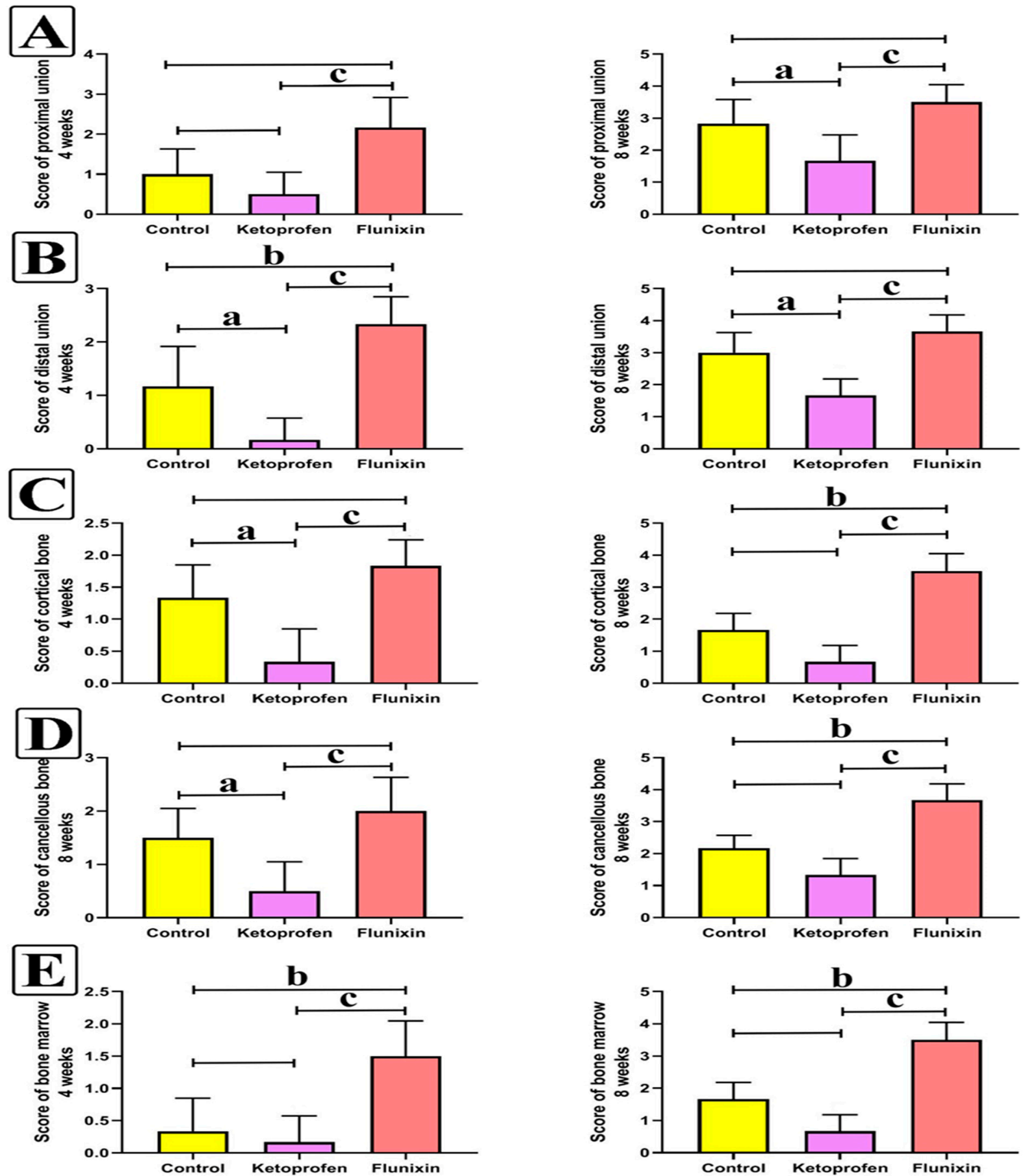

Figure 6. Histopathology statistics of H\&E staining. (A): Score of the proximal union at 4 and 8 weeks. (B): Score of the distal union at 4 and 8 weeks. (C): Score of the cortical bone at 4 and 8 weeks. (D): Score of the cancellous bone at 4 and 8 weeks. (E): Score of the bone marrow at 4 and 8 weeks. Data are expressed as mean \pm SD. Superscript letters indicate the significance level: a denotes the significant difference between the ketoprofen group and the control group, $b$ denotes the significant difference between the FM group and the control group, and c: denotes the significant difference between the FM and the ketoprofen groups $(p<0.05)$. 


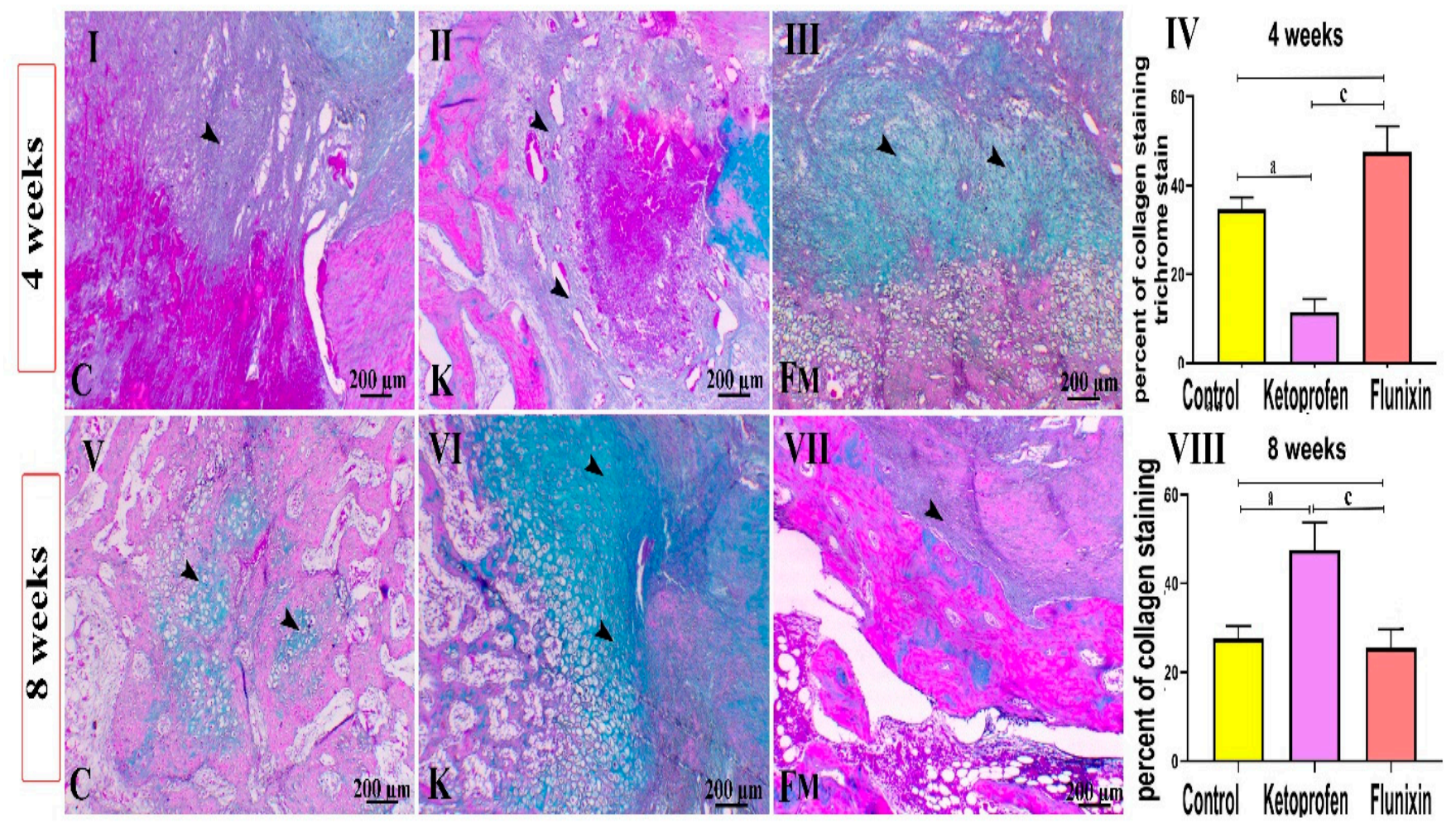

Figure 7. Photomicrographs of different Masson's trichrome-stained femur sections of different groups (8 weeks). C indicates the control group, $\mathrm{K}$ indicates the ketoprofen group, and FM indicates the flunixin meglumine group. FM treated animals showed early fibroblastic activity, whereas the ketoprofen group still demonstrated pronounced fibrosis in the 8th week. Masson's trichrome stain. Data are expressed as mean \pm SD. Superscript letters indicate the significance level; a denotes the significant difference between the ketoprofen and the control groups; c: denotes the significant difference between the FM and the ketoprofen groups. $(p<0.05)$. (I, V) denote control group at 4 , and 8 weeks. (II, VI) denote control group at 4 , and 8 weeks. (III,VII) denote control group at 4 , and 8 weeks. (IV) denotes statistical graph to the percent of trichrome staining at 4 weeks between control, ketoprofen, and FM groups. (VIII) denotes statistical graph to the percent of trichrome staining at 8 weeks between control, ketoprofen, and FM groups.

\subsection{Immunohistochemical Findings VEGF Immunostaining}

As illustrated in Figure 8, the FM-treated group showed a marked expression of VEGF antibody within the soft callus tissue within the formed osseous cells and granulation tissues. Meanwhile, the ketoprofen-treated group showed a significant decrease in VEGF immunostaining within the granulation tissues in the 4th week study. In the 8th week, the expression was also increased within the bone marrow tissues in the FM group, whereas the ketoprofen group showed a mild expression of the VEGF within the hard callus tissues. The quantitative scoring of positive area expression of the VEGF antibody demonstrated a significant increase in VEGF immunostaining within the FM group at the 4th and 8th week studies compared to the control group $(p<0.05)$. There was also a significant decrease in VEGF expression within the soft and hard callus tissues of the ketoprofen group upon both sacrifice times $(p<0.05)$. 

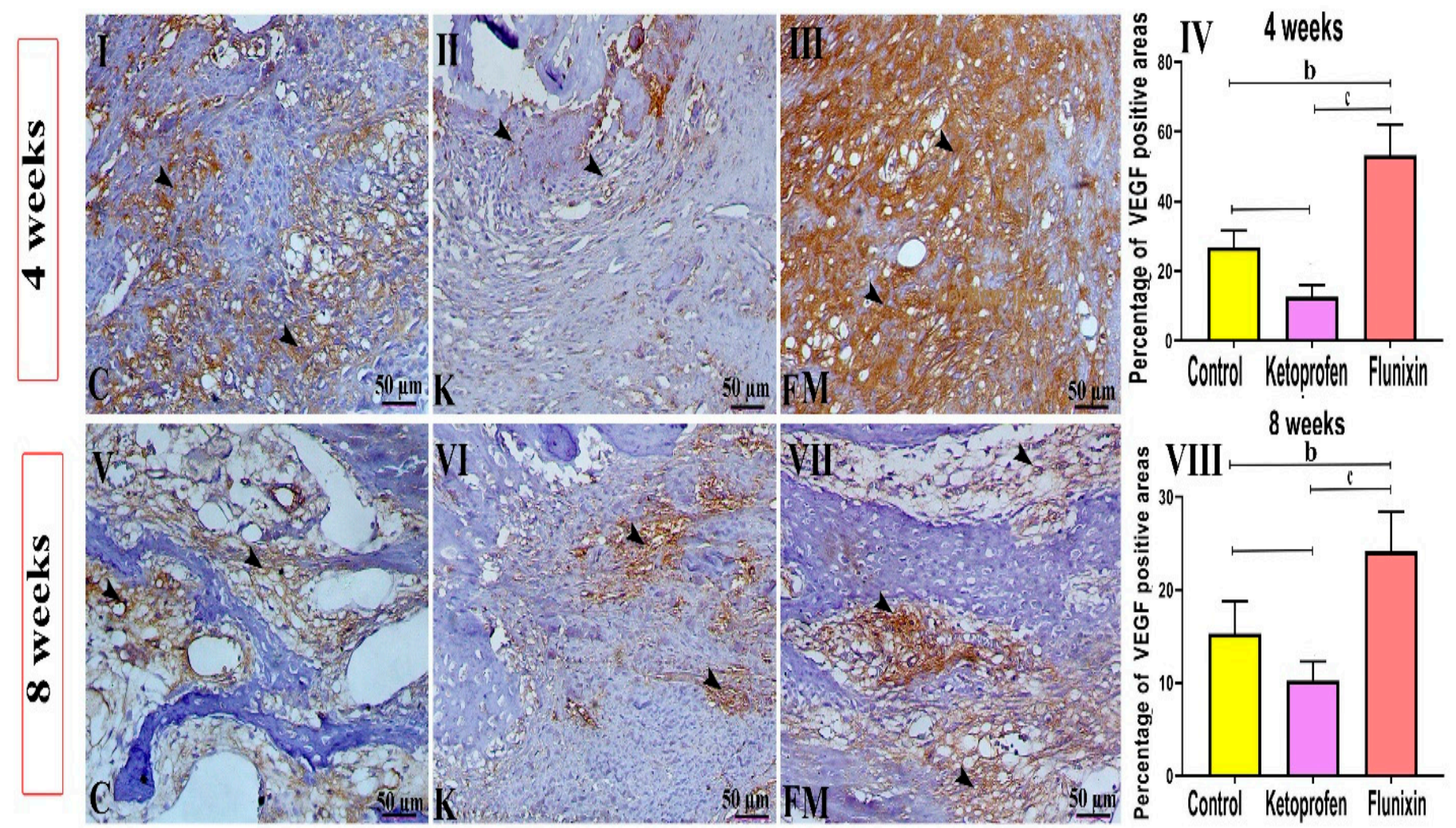

Figure 8. Photomicrographs of different VEGF IHC-stained tibial sections of different groups. C indicates the control group, $\mathrm{K}$ indicates the ketoprofen group, and FM indicates the flunixin meglumine group. Ketoprofen-treated animals showed a marked decrease in the expression of VEGF antibody, and FM-treated animals showed marked VEGF immunostaining (arrowheads indicate positive expression). Bar $=50 \mu \mathrm{m}$. Data are expressed as mean $\pm \mathrm{SD}$. Superscript letters indicate the significance level; $\mathrm{b}$ denotes the significant difference between the FM and control groups. c: denotes the significant difference between the FM and the ketoprofen groups. $(p<0.05)(\mathbf{I}, \mathbf{V})$ denote control group at 4 , and 8 weeks. (II,VI) denote control group at 4 , and 8 weeks. (III,VII) denote control group at 4 , and 8 weeks. (IV) denotes statistical graph to the percent of trichrome staining at 4 weeks between control, ketoprofen, and FM groups. (VIII) denotes statistical graph to the percent of trichrome staining at 8 weeks between control, ketoprofen, and FM groups.

\section{Discussion}

Bone healing could be affected by multiple factors, such as postoperative treatment [36-39]. NSAIDs are commonly used postoperatively, but they might have diverse effects on bone healing $[3,4,7]$. Some delay the bone healing process [11,40,41], while others do not affect bone healing [12]. For the first time, this study has revealed the potential effect of one of the NSAIDs, FM, on bone fracture healing by enhancing angiogenesis at the fracture site, as reflected by VEGF expression and increasing osseous tissue formation. However, ketoprofen, like other NSAIDs, causes a delay in bone fracture.

Importantly, serial radiographs have been used to monitor the progress of bone fracture healing [42], including aspects of bone callus formation, bone union, and bone remodeling $[30,43,44]$. In this study, the radiographic findings revealed that FM improved fracture healing by improving callus formation, bone union, and bone remodeling. In stark contrast, ketoprofen delayed bone fracture healing by decreasing bone callus formation, bone union, and bone remodeling. The study's findings are in harmony with previous studies that reported the delayed effect of ketoprofen on bone fracture healing in rabbits and cats $[40,41]$.

Furthermore, good bone healing requires suitable stability, blood, and oxygen supply [44]. Several previous reports on different species (rabbits and rats) have shown the effect of FM on skin healing [24,45]. These studies proved that FM has adverse effects on the inflammatory phase of wound repair but not on the proliferative phase when fibroplasia 
is a major factor in wound strength [24]. Moreover, FM was not found to adversely influence breaking strength and wound contraction [45]. A previous study induced fibroblast proliferation in tendon injury, which fastened the tendon's healing process [23]. In this study at 4 postoperative weeks, the histological results showed that FM had the same effect as that of the control and ketoprofen groups on osteoblast by increasing osseous tissues expression at the fracture site.

A bone matrix consists of nonorganic and organic components [46-49]. Collagen is the most copious protein in bone and represents approximately $90 \%$ of its organic matrix $[49,50]$. The collagen expression at a fracture site indicates osteogenesis of the mesenchymal stem cells (MSCs) $[48,49]$. In this study, the FM group showed a higher expression of collagen fibers at 4 weeks than those of the ketoprofen and the control groups, which were decreased by the effect of remodeling at 8 weeks.

In this study, ketoprofen stimulated fibroblast aggregation at the fracture site. The mechanism by which ketoprofen causes this fibroblast aggregation is still unknown and needs further research. It seems that it could be beneficial to soft tissue. However, in bone, it might hinder healing, as evidenced by the higher expression of fibroblast at the fracture site in the ketoprofen-treated group compared to the control and FM groups at the same stage (4 postoperative weeks). However, the study results contrasted with some previous reports that revealed that ketoprofen induced apoptosis in fibroblasts [51]. Furthermore, FM was found to enhance the healing process in contrast to other NSAIDs such as ketoprofen, which delayed this process through its influence on COX-1 and COX-2 enzymes. Some previous reports have revealed that prostaglandin E2 (PGE2) might regulate osteoblast behavior via the relative expression of the receptor activator of nuclear factor kappa-B ligand and osteoprotegerin, which is regulated through COX-1 and COX-2 enzymes. The inhibition of COX isozymes and the consequent decrease in PGE2 may be the mechanisms by which NSAIDs delays bone healing [4].

The available literature suggests that FM does not affect neovascularization, while ketoprofen reduces neovascularization [39,52,53]. More importantly, vascular supply at the fracture site is an essential step in the healing process since a good blood supply means plenty of the oxygen and nutrients required for fast healing [54]. Furthermore, the key physiological regulator of angiogenesis during embryogenesis and skeletal growth is VEGF $[54,55]$. A previous study revealed that FM stimulates angiogenesis in the wound site, enhancing tendon healing [23]. Similarly, in this study, FM was found to stimulate angiogenesis at the fracture site, which was obvious from the expression of VEGF at the fracture site in the FM group. However, no expression was reported in the other groups, suggesting that the FM group enhanced bone healing and the control and ketoprofen groups did not.

\section{Conclusions}

Given the present findings and their direct clinical applications, the use of FM after orthopedic surgery as a pain killer and anti-inflammatory is recommended. This study has proven for the first time that FM can enhance the bone healing process, callus formation, bone union, and remodeling in rabbits. Meanwhile, ketoprofen has an adverse influence on the bone healing process. The main limitations of the present study included its experimental fracture model that created osteotomy, significant violation of natural biology to cause the fracture, limited number of samples, short-term doses of ketoprofen, and lack of information regarding the detailed mechanisms by which ketoprofen delays healing. It would be interesting to investigate the effect of the short-term and long-term administration of ketoprofen on fracture healing to explain the main mechanisms by which ketoprofen may influence non-bone union and delay bone fracture healing. Future research to explore the mechanistic pathways involved in the underlying effects of FM on bone healing is also warranted.

Author Contributions: M.E., G.E., M.S. and A.A. were involved in the conception of the idea, methodology design, data analysis, and interpretation. W.A., E.K.E. and R.S.B. contributed their 
scientific advice and prepared the manuscript for publication and revision. All authors have read and agreed to the published version of the manuscript.

Funding: This research received no external funding.

Institutional Review Board Statement: The study was conducted according to the guidelines of the Declaration of Helsinki, and approved by the Institutional Review Board of the Faculty of Veterinary Medicine, Kafrelsheikh University, reviewed and approved the procedures and protocols involved in both the animal welfare and surgical techniques of this study under approval number KFS-2020/7.

Data Availability Statement: The data that support the findings of this study are available on request from the corresponding authors.

Acknowledgments: This work was supported by the Taif University Researchers Supporting Program, Taif University, Saudi Arabia (Project number: TURSP-2020/269).

Conflicts of Interest: The authors declare no conflict of interest that could have potentially influenced the results of this study.

\section{References}

1. Salih, S.I.; Al-Falahi, N.H.; Saliem, A.H.; Abedsalih, A.N. Effectiveness of platelet-rich fibrin matrix treated with silver nanoparticles in fracture healing in rabbit model. Vet. World 2018, 11, 944. [CrossRef]

2. Pountos, I.; Georgouli, T.; Bird, H.; Kontakis, G.; Giannoudis, P.V. The effect of antibiotics on bone healing: Current evidence. Expert Opin. Drug Saf. 2011, 10, 935-945. [CrossRef]

3. Cottrell, J.; O'Connor, J.P. Effect of non-steroidal anti-inflammatory drugs on bone healing. Pharmaceuticals 2010, 3, 1668-1693. [CrossRef]

4. Wheatley, B.M.; Nappo, K.E.; Christensen, D.L.; Holman, A.M.; Brooks, D.I.; Potter, B.K. Effect of NSAIDs on bone healing rates: A meta-analysis. J. Am. Acad. Orthop. Surg. 2019, 27, e330-e336. [CrossRef]

5. Brown, K.M.; Saunders, M.M.; Kirsch, T.; Donahue, H.J.; Reid, J.S. Effect of COX-2-specific inhibition on fracture-healing in the rat femur. JBJS 2004, 86, 116-123. [CrossRef]

6. Lisowska, B.; Kosson, D.; Domaracka, K. Positives and negatives of nonsteroidal anti-inflammatory drugs in bone healing: The effects of these drugs on bone repair. Drug Des. Dev. Ther. 2018, 12, 1809. [CrossRef]

7. Pountos, I.; Georgouli, T.; Calori, G.M.; Giannoudis, P.V. Do nonsteroidal anti-inflammatory drugs affect bone healing? A critical analysis. Sci. World J. 2012, 2012, 606404. [CrossRef]

8. Nagano, A.; Arioka, M.; Takahashi-Yanaga, F.; Matsuzaki, E.; Sasaguri, T. Celecoxib inhibits osteoblast maturation by suppressing the expression of Wnt target genes. J. Pharmacol. Sci. 2017, 133, 18-24. [CrossRef]

9. Marquez-Lara, A.; Hutchinson, I.D.; Nuñez, F., Jr.; Smith, T.L.; Miller, A.N. Nonsteroidal anti-inflammatory drugs and bonehealing: A systematic review of research quality. JBJS Rev. 2016, 4, e4. [CrossRef]

10. Lack, W.D.; Fredericks, D.; Petersen, E.; Donovan, M.; George, M.; Nepola, J.; Smucker, J.; Femino, J.E. Effect of aspirin on bone healing in a rabbit ulnar osteotomy model. JBJS 2013, 95, 488-496. [CrossRef]

11. Dimmen, S.; Engebretsen, L.; Nordsletten, L.; Madsen, J.E. Negative effects of parecoxib and indomethacin on tendon healing: An experimental study in rats. Knee Surg. Sports Traumatol. Arthrosc. 2009, 17, 835-839. [CrossRef]

12. Van Esch, R.W.; Kool, M.M.; van As, S. NSAIDs can have adverse effects on bone healing. Med. Hypotheses 2013, 81, 343-346. [CrossRef]

13. Aliuskevicius, M.; Østgaard, S.E.; Hauge, E.M.; Vestergaard, P.; Rasmussen, S. Influence of Ibuprofen on Bone Healing After Colles' Fracture: A Randomized Controlled Clinical Trial. J. Orthop. Res. 2020, 38, 545-554. [CrossRef] [PubMed]

14. Hjorthaug, G.A.; Søreide, E.; Nordsletten, L.; Madsen, J.E.; Reinholt, F.P.; Niratisairak, S.; Dimmen, S. Short-term perioperative parecoxib is not detrimental to shaft fracture healing in a rat model. Bone Jt. Res. 2019, 8, 472-480. [CrossRef] [PubMed]

15. Zarghi, A.; Arfaei, S. Selective COX-2 Inhibitors: A Review of Their Structure-Activity Relationships. Iran. J. Pharm. Res. 2011, 10, 655-683.

16. Mitchell, J.A.; Warner, T.D. Cyclo-oxygenase-2: Pharmacology, physiology, biochemistry and relevance to NSAID therapy. Br. J. Pharmacol. 1999, 128, 1121-1132. [CrossRef] [PubMed]

17. Kam, P.; See, A.U.L. Cyclo-oxygenase isoenzymes: Physiological and pharmacological role. Anaesthesia 2000, 55, 442-449. [CrossRef]

18. Wasnik, S.; Lakhan, R.; Baylink, D.J.; Rundle, C.H.; Xu, Y.; Zhang, J.; Qin, X.; Lau, K.-H.W.; Carreon, E.E.; Tang, X. Cyclooxygenase 2 augments osteoblastic but suppresses chondrocytic differentiation of CD90+ skeletal stem cells in fracture sites. Sci. Adv. 2019, 5, eaaw2108. [CrossRef]

19. Lisowska, B.; Kosson, D.; Domaracka, K. Lights and shadows of NSAIDs in bone healing: The role of prostaglandins in bone metabolism. Drug Des. Dev. Ther. 2018, 12, 1753. [CrossRef]

20. Vuolteenaho, K.; Moilanen, T.; Moilanen, E. Non-steroidal anti-inflammatory drugs, cyclooxygenase-2 and the bone healing process. Basic Clin. Pharmacol. Toxicol. 2008, 102, 10-14. [CrossRef] 
21. Nyangoga, H.; Aguado, E.; Goyenvalle, E.; Baslé, M.F.; Chappard, D. A non-steroidal anti-inflammatory drug (ketoprofen) does not delay $\beta$-TCP bone graft healing. Acta Biomater. 2010, 6, 3310-3317. [CrossRef]

22. Urrutia, J.; Mardones, R.; Quezada, F. The effect of ketoprophen on lumbar spinal fusion healing in a rabbit model. J. Neurosurg. Spine 2007, 7, 631-636. [CrossRef] [PubMed]

23. Behfar, M.; Hobbenaghi, R.; Sarrafzadeh-Rezaei, F. Effects of flunixin meglumine on experimental tendon wound healing: A histopathological and mechanical study in rabbits. Vet. Res. Forum Int. Q. J. 2013, 4, 233.

24. Donner, G.; Ellison, G.; Peyton, L.; Crowley, A.; Szempruch, N.; Williams, J. Effect of flunixin meglumine on surgical wound strength and healing in the rat. Am. J. Vet. Res. 1986, 47, 2247-2251. [PubMed]

25. Reppert, E.J.; Kleinhenz, M.D.; Montgomery, S.R.; Bornheim, H.N.; Magnin, G.; Sidhu, P.K.; Zhang, Y.; Joo, H.; Coetzee, J.F. Pharmacokinetics and pharmacodynamics of intravenous and transdermal flunixin meglumine in meat goats. J. Vet. Pharmacol. Ther. 2019, 42, 309-317. [CrossRef]

26. Lane, N.E.; Nyman, J.; Uppuganti, S.; Chaudhari, A.; Aguirre, J.; Shidara, K.; Liu, X.; Yao, W.; Kimmel, D. Inhibition of vascular endothelial growth factor in young adult mice causes low bone blood flow and bone strength with no effect on bone mass in trabecular regions. Bone Rep. 2019, 10, 100210. [CrossRef] [PubMed]

27. Greenberg, D.A.; Jin, K. Vascular endothelial growth factors (VEGFs) and stroke. Cell. Mol. Life Sci. 2013, 70, 1753-1761. [CrossRef]

28. Hirashima, M. Regulation of endothelial cell differentiation and arterial specification by VEGF and Notch signaling. Anat. Sci. Int. 2009, 84, 95-101. [CrossRef]

29. de Sousa Segundo, F.A.; de Sousa Costa, E.I.; de Azevedo, A.S.; de Araújo, A.L.; de França Silva, A.C.; de Lima, G.G.; de Sá, M.J.C. Platelet-rich plasma, hydroxyapatite, and chitosan in the bone and cartilaginous regeneration of femoral trochlea in rabbits: Clinical, radiographic, and histomorphometric evaluations. J. Healthc. Eng. 2018, 2018, 6917958.

30. Yoshino, O.; Brady, J.; Young, K.; Hardy, B.; Matthys, R.; Buxton, T.; Appleyard, R.; Tomka, J.; Dabirrahmani, D.; Woodford, P. Reamed locked intramedullary nailing for studying femur fracture and its complications. Eur. Cell Mater. 2017, 34, 99-107. [CrossRef]

31. Gahlod, T.R.; Dhakate, M.; Upadhye, S.A.S.; Bawaskar, S. Management of femoral fracture with the use of horn peg in canine. Vet. World 2010, 3, 37.

32. Suvarna, K.S.; Layton, C.; Bancroft, J.D. Bancroft's Theory and Practice of Histological Techniques, 8th ed.; Elsevier: Beijing, China, 2019.

33. Heiple, K.G.; Goldberg, V.M.; Powell, A.E.; Bos, G.D.; Zika, J.M. Biology of cancellous bone grafts. Orthop. Clin. N. Am. 1987, 18, 179-185. [CrossRef]

34. Bigham, A.; Dehghani, S.; Shafiei, Z.; Nezhad, S.T. Xenogenic demineralized bone matrix and fresh autogenous cortical bone effects on experimental bone healing: Radiological, histopathological and biomechanical evaluation. J. Orthop. Traumatol. 2008, 9 , 73-80. [CrossRef] [PubMed]

35. Saber, S.; Khalil, R.M.; Abdo, W.S.; Nassif, D.; El-Ahwany, E. Olmesartan ameliorates chemically-induced ulcerative colitis in rats via modulating NFkB and Nrf-2/HO-1 signaling crosstalk. Toxicol. Appl. Pharmacol. 2019, 364, 120-132. [CrossRef] [PubMed]

36. Claes, L.; Recknagel, S.; Ignatius, A. Fracture healing under healthy and inflammatory conditions. Nat. Rev. Rheumatol. 2012, 8 , 133-143. [CrossRef] [PubMed]

37. Mirhadi, S.; Ashwood, N.; Karagkevrekis, B. Factors influencing fracture healing. Trauma 2013, 15, 140-155. [CrossRef]

38. Alemdaroğlu, K.B.; Tiftikçi, U.; Iltar, S.; Aydoğan, N.H.; Kara, T.; Atlihan, D.; Ateşalp, A.S. Factors Affecting the Fracture Healing in Treatment of Tibial Shaft Fractures With Circular External Fixator. Injury 2009, 40, 1151-1156. [CrossRef] [PubMed]

39. Jarolmasjed, S.; Shahbazfar, A.-A.; Mohammadpour, H. Histpathological Anti-inflammatory Effects of Flunixin Meglumine and Ketoprofen on Excised Rat Tendon. Iran. J. Vet. Surg. 2015, 10, 53-58.

40. Yaseen, F.N.; Taqa, G.A. Effect of Ketoprofen and Paracetamol on Bone Mineral Density in Rabbits. Int. J. Enhanc. Res. Sci. Technol. Eng. 2018, 7, 69-78.

41. Moarabi, A.; Mossalla Nejad, B.; Imani Rastabi, H.; Baniadam, A.; Hoseini, H. Evaluation of Adverse Effects of Ketoprofen Following Experimental Tibial Osteotomy in Cats. Iran. Vet. J. 2016, 12, 99-110.

42. Nicholls, P.J.; Berg, E.; Bliven, F.E., Jr.; Kling, J.M. X-ray diagnosis of healing fractures in rabbits. Clin. Orthop. Relat. Res. 1979, 142, 234-236. [CrossRef]

43. Ochi, H.; Hara, Y.; Asou, Y.; Harada, Y.; Nezu, Y.; Yogo, T.; Shinomiya, K.; Tagawa, M. Effects of long-term administration of carprofen on healing of a tibial osteotomy in dogs. Am. J. Vet. Res. 2011, 72, 634-641. [CrossRef]

44. Einhorn, T.A.; Gerstenfeld, L.C. Fracture healing: Mechanisms and interventions. Nat. Rev. Rheumatol. 2015, 11, 45. [CrossRef]

45. Tovar, L.; Agut, A.; Sanchez-Valverde, M.; Lasaosa, J.; Gomez, M. Effect of flunixin meglumine on surgical skin wound healing in the rabbit. Arch. Med. Vet. 1992, 24, 169-174.

46. Poundarik, A.A.; Wu, P.-C.; Evis, Z.; Sroga, G.E.; Ural, A.; Rubin, M.; Vashishth, D. A direct role of collagen glycation in bone fracture. J. Mech. Behav. Biomed. Mater. 2015, 52, 120-130. [CrossRef] [PubMed]

47. Han, Y.; Gomez, J.; Hua, R.; Xiao, P.; Gao, W.; Jiang, J.X.; Wang, X. Removal of glycosaminoglycans affects the in situ mechanical behavior of extrafibrillar matrix in bone. J. Mech. Behav. Biomed. Mater. 2021, 123, 104766. [CrossRef] [PubMed]

48. Arai, Y.; Choi, B.; Kim, B.J.; Park, S.; Park, H.; Moon, J.J.; Lee, S.-H. Cryptic ligand on collagen matrix unveiled by MMP13 accelerates bone tissue regeneration via MMP13/Integrin $\alpha 3$ /RUNX2 feedback loop. Acta Biomater. 2021, 125, 219-230. [CrossRef] [PubMed] 
49. Gao, G.; Schilling, A.F.; Yonezawa, T.; Wang, J.; Dai, G.; Cui, X. Bioactive nanoparticles stimulate bone tissue formation in bioprinted three-dimensional scaffold and human mesenchymal stem cells. Biotechnol. J. 2014, 9, 1304-1311. [CrossRef]

50. Barker, A.J.; Arthur, A.; DeNichilo, M.O.; Panagopoulos, R.; Gronthos, S.; Anderson, P.J.; Zannettino, A.C.; Evdokiou, A.; Panagopoulos, V. Plant-derived soybean peroxidase stimulates osteoblast collagen biosynthesis, matrix mineralization, and accelerates bone regeneration in a sheep model. Bone Rep. 2021, 14, 101096. [CrossRef] [PubMed]

51. Zuniga, J.; Fuenzalida, M.; Guerrero, A.; Illanes, J.; Dabancens, A.; Diaz, E.; Lemus, D. Effects of steroidal and non steroidal drugs on the neovascularization response induced by tumoral TA3 supernatant on CAM from chick embryo. Biol. Res. 2003, 36, 233-240. [CrossRef]

52. Manzano-Moreno, F.J.; Costela-Ruiz, V.J.; Melguizo-Rodríguez, L.; Illescas-Montes, R.; García-Martínez, O.; Ruiz, C.; RamosTorrecillas, J. Inhibition of VEGF gene expression in osteoblast cells by different NSAIDs. Arch. Oral Biol. 2018, 92, 75-78. [CrossRef]

53. Sakayama, K.; Kidani, T.; Miyazaki, T.; Shirakata, H.; Kimura, Y.; Kamogawa, J.; Masuno, H.; Yamamoto, H. Effect of ketoprofen in topical formulation on vascular endothelial growth factor expression and tumor growth in nude mice with osteosarcoma. J. Orthop. Res. 2004, 22, 1168-1174. [CrossRef] [PubMed]

54. Bahney, C.S.; Zondervan, R.L.; Allison, P.; Theologis, A.; Ashley, J.W.; Ahn, J.; Miclau, T.; Marcucio, R.S.; Hankenson, K.D. Cellular biology of fracture healing. J. Orthop. Res. 2019, 37, 35-50. [CrossRef] [PubMed]

55. Orth, M.; Shenar, A.K.; Scheuer, C.; Braun, B.J.; Herath, S.C.; Holstein, J.H.; Histing, T.; Yu, X.; Murphy, W.L.; Pohlemann, T. VEGF-loaded mineral-coated microparticles improve bone repair and are associated with increased expression of epo and RUNX-2 in murine non-unions. J. Orthop. Res. 2019, 37, 821-831. [CrossRef] 